\title{
Demographics of mass customization: a global study of manufacturing plants
}

\author{
Giovani José Caetano da Silveira ${ }^{\mathrm{a} *}$, Flávio Sanson Fogliatto ${ }^{\mathrm{b}}$, Andrey Fendyura \\ a*Haskayne School of Business, University of Calgary, Calgary, Canada, giovani.dasilveira@haskayne.ucalgary.ca \\ bUniversidade Federal do Rio Grande do Sul, Porto Alegre, RS, Brasil
}

\begin{abstract}
This study explores the demographic configuration of mass customization (MC) manufacturing plants. It uses cluster analysis, ANOVA and correspondence analysis to test for differences in business unit size, location, and supply chain structure between MC and non-MC producers across the globe. The analysis uses data from an international survey of manufacturers of metal products, machinery, and instruments from 21 countries. Results indicate no significant differences in size, but significant differences in location and supply chain indicators between MC and non-MC plants. We also find renewed evidence of the positioning of MC plants in Hayes \& Wheelwright's (1979) product and process matrix.
\end{abstract}

Keywords

Mass customization. Cluster analysis. Survey.

\section{Introduction}

Mass customization (MC) is a phenomenon in evolution. Over the last decades and particularly in manufacturing, $\mathrm{MC}$ has evolved from being a niche competitive approach to becoming a widely adopted strategy focused on improved response to customer requirements (Aigbedo, 2009; Matzler et al., 2011). Studies report case applications of MC across a broadening range of industries from traditional, e.g. automotive (Ro et al., 2007), food manufacturing (Mclntosh et al., 2010), and apparel (Au \& Ma, 2010) to unconventional, e.g. biomedicine (McMains, 2005; Pallari et al., 2010). Such applications have been facilitated by an ever-increasing range of technologies and methods that enable fast delivery of variety at competitive cost. A number of alternatives have become available to industrial managers and engineers, ranging from cutting-edge rapid manufacturing (Atzeni et al., 2010) and 3D computer-aided design technologies (Au \& Ma, 2010), to improved product and process configurations such as product modularity (Ro et al., 2007), and time and form postponement (Su et al., 2005).
Formerly limited to companies in close contact with customers and their demands (Da Silveira et al., 2001), MC is currently being adopted by an increasing number of companies with different strategic and technological profiles. Studying common characteristics of such evolving sample of companies becomes paramount to keep the theory and practice of MC in pace. That is the focus of our attention in this paper.

This study explores the demographic configuration of MC manufacturing plants. In particular, it compares the business unit size, location, and supply chain configuration of $\mathrm{MC}$ versus non-MC manufacturers of metal parts, machinery and equipment. Previous studies based on single or multiple case studies described specific MC implementations in manufacturers both large (Feitzinger \& Lee, 1997) or small (Dean et al., 2009), located in countries as diverse as Canada (Dean et al., 2009) and China (Fan \& Huang, 2007). However, no large sample statistics were explored in those studies. In fact, only a few studies such as Liu et al. (2006), Lai et al. (2012), and Trentin et al. (2012) (all using data from the High Performance 
Manufacturing Project) appear to have explored relationships between $\mathrm{MC}$ adoption, and manufacturing organizational variables with large international samples.

There are two important contributions in this paper. First, we present an empirical analysis of the demographics of MC and non-MC producers using a multi-national sample of 695 manufacturers of metal parts, machinery, and equipment. The data were collected in the fifth International Manufacturing Strategy Survey (IMSS-V) in 2009, and includes responses from 21 countries in different continents. Our findings point to (i) the prevalence of $\mathrm{MC}$ producers in Asian countries, (ii) the emphasis in MC plants on developing coordination with strategic suppliers, and (iii) the homogeneity in company size among MC and non-MC producers.

Second, and following studies such as Safizadeh et al. (1996), Ahmad \& Schroeder (2002), Ariss \& Zhang (2002), and Olhager \& Rudberg (2003), we present new empirical evidence on the positioning of MC plants in Hayes \& Wheelwright's (1979) product and process matrix (PPM), based on cluster analysis. A novel clustering variable is proposed for that, considering the amount of mass and customized processes present in the manufacturers surveyed in the study sample. Our findings pointed to the existence of three distinct groups of manufacturers, positioned above, below and along the PPM main diagonal. The groupings enabled the estimation of relevant demographic characteristics of $\mathrm{MC}$ and non-MC producers.

In addition to the present introduction there are six sections in this paper. In section 2 we present the study hypotheses, backed by relevant pertinent literature. In section 3 we describe the data used to test the hypotheses, and detail the cluster analysis performed on it. Criterion variables associated with the hypotheses in section 2 are presented in section 4 , followed by the results obtained on the hypothesis tests in section 5. In the last two sections we present a discussion on results in previous sections, and general conclusions.

\section{Background and hypotheses}

\subsection{Mass customization}

Mass customization (MC) is an operations strategy that aims to deliver personalized goods or services at competitive cost (Gilmore \& Pine, 1997; Duray, 2002). It provides superior value by allowing customers to choose and often co-design products incorporating unique specifications (Franke \& Schreier, 2008; Merle et al., 2008). As pointed out by Safizadeh et al.
(1996), Grover \& Malhotra (1999), Ahmad \& Schroeder (2002) and Olhager \& Rudberg (2003) among others, advanced technologies and methods such as computeraided design (CAD) and product modularity allow manufacturers to deliver such customized products using linear processes; this combination positions MC manufacturers off the main diagonal of the Hayes \& Wheelwright's (1979) PPM.

MC applications evolved significantly since the concept was defined in Davis (1987) and Pine 11 (1993). The first cases included consumer products such as jeans (Zipkin, 2001), bicycles (Kotha, 1995; Zipkin, 2001), and printers (Feitzinger \& Lee, 1997) that were well suited to modular design. Further applications included services such as construction (Barlow et al., 2003) and intermediate parts suppliers (Pine 11 et al., 1995). More recently, MC has been adopted at the other end of the personalization scale, turning high-end goods such as biomedical components (McMains, 2005; Pallari et al., 2010) more affordable.

Thus, MC has evolved from being a niche approach to become a widely adopted manufacturing strategy (Aigbedo, 2009; Matzler et al., 2011). Its broad dissemination in industry may have various explanations. First, there has been increased consumer demand for personalized goods and services (Ahmad et al., 2010). Second, new information technologies offer new interfaces for user-initiated design (Wind \& Rangaswamy, 2001; Dewan et al., 2003; Ong et al., 2006). Third, flexible technologies such as CAD and rapid prototyping are less expensive and more widely applicable (Gould, 2004; McMains, 2005).

Following on Safizadeh et al. (1996), Grover \& Malhotra (1999), Ahmad \& Schroeder (2002), Ariss \& Zhang (2002), and Olhager \& Rudberg (2003) among others, there should be a significant number of manufacturers in our sample operating off the main diagonal in Hayes \& Wheelwright's (1979) PPM by combining high volume processes such as linear and continuous configurations with high product variation.

- H1. The study sample will include a unique group of MC plants producing high product variety based on high volume process configurations.

Past studies found alternative levels of support to this hypothesis. Safizadeh et al. (1996) found that 13 of 142 U.S. manufacturers offered medium to high levels of customization while operating with linear or continuous processes. Using data from the World Class Manufacturing (WCM) survey, Ahmad \& Schroeder (2002) found that two out of four manufacturing clusters provided high levels of customization that did not match their process 
configurations. Ariss \& Zhang's (2002) analysis of 31 manufacturers from Michigan, US found that flexibility capability minimized performance gaps between companies operating on and off the PPM main diagonal. Olhager \& Rudberg (2003) found that two out of eight Swedish manufacturers in their multiple-case analysis were located in the MC corner of the PPM.

\subsection{Size and location}

We expect to find no significant differences in size or location between MC and non-MC plants. Effects of firm size, measured by number of employees, are often considered in manufacturing strategy models of adoption; one justification is that larger firms usually have more resources to implement advanced practices or technologies (Boyer et al., 1996; Koufteros et al., 2007; Liu et al., 2006). However, we argue that this rationale is not applicable to MC.

One of the unique features of $\mathrm{MC}$ is that it can be supported by methods and technologies having different levels of complexity and cost. Thus, even small and medium enterprises (SMEs) can pursue MC strategies providing they overcome organizational challenges (Svensson \& Barfod, 2002) and learn how to apply advanced technologies including IT to their processes (Dean et al., 2009). For example, Bateman \& Cheng (2006) discuss at length how a CAD system could be adapted to support "devolved manufacturing" in a small firm. This could explain why liu et al. (2006) found no significant correlation between "plant size" and $\mathrm{MC}$ capability in an international manufacturing survey. This leads to the second study hypothesis:

- H2. There will be no significant differences in size between MC and non-MC plants in the study sample.

Likewise, the broad technological and methodological basis may facilitate MC development across different parts of the world including developed and developing countries. Although we may be witnessing changes in long-established regional advantages (for example, increasing wages in China - see Yang et al. (2010) for a longitudinal analysis), manufacturing in North America and Europe is still more reliant on process technology and less on labor-intensive tasks than manufacturing in Asia and Latin America (see data in Schwab \& Sala-iMartin (2011): 510). However, MC is supported by a mix of labor and technology-embedded capabilities (Kotha, 1995), the balance of which may vary from case to case. Thus, MC processes could be adapted to fit regional advantages such as relying more on technology where labor is more expensive, and viceversa. For example, Atzeni et al. (2010) suggest that rapid manufacturing (RM) could substitute injection molding to enable "medium volume" production in Western Europe. These arguments suggest that MC may be indeed a global phenomenon, even though specific configurations of MC may be contingent on local factors. This leads to the third hypothesis:

- H3. There will be no significant differences in location between MC and non-MC plants in the study sample.

\subsection{Supply chain}

The design and production of MC products often depends on strong collaboration with a few distinctive suppliers (Galbraith, 1977, reviewed in Trentin et al., 2012). One of the cornerstones of transaction cost theory (TCT) is that maintaining arms-length relationships with external partners may turn outsourcing expensive to producers requiring frequent information exchanges with suppliers (Malone, 1987; Clemons et al., 1993). Therefore, focus on customization calls for more integrated supply chain structures (Mikkola \& Skjott-Larsen, 2004; Salvador et al., 2004; Trentin et al., 2012) which, according to TCT, can rely on either straight verticalization or hybrid coordination models such as defined by Williamson (1985). However, as indicated by Lai et al. (2012), the extended resource-based view of the firm (ERBV) suggests that the hybrid form (i.e. supply chain collaboration) is likely to be more prevalent among MC providers, because MC design and production depends on a broad set of capabilities.

Furthermore, MC from a technical view is enabled by a series of capabilities and practices that are more easily implemented through integration with supply chain partners. Frequent and unplanned changes in customer requirements and design specifications demand intensive information exchange across the supply chain to enable product design and process planning (Liao et al., 2011; Peng et al., 2011; Trentin et al., 2012). Such information is often relayed through IT integration (Peng et al., 2011). Moreover, common MC techniques such as form postponement (Mikkola \& Skjott-Larsen, 2004; Salvador et al., 2004; Su et al., 2005) and concurrent engineering (Tu et al., 2004; Kincade et al., 2007) rely often on forms of synchronization between supply chain partners (e.g. of strategic goals, design capabilities, process scheduling, logistics, etc. - see, for example Salvador et al. (2004) and Liao et al. (2011)), which are not compatible with market-based relationships and short-term contracts. These arguments lead to the final two study hypotheses: 
- H4. MC plants will maintain more strategic supplier relationships and a smaller supplier base than non-MC plants in the study sample.

- H5. In selecting suppliers, MC plants will give more importance to coordination capability criteria than non-MC plants in the study sample.

Lai et al. (2012) investigated a similar relationship between MC and "supplier integration" in a sample of 287 manufacturers from nine countries. They found no significant support to the hypothesis. However, Trentin et al. (2012) did find a significant higher level of "environmental management" (a construct involving "supplier partnership" together with two other scales) in companies with higher MC capabilities.

\section{Data}

We use data from the fifth edition of the International Manufacturing Strategy Survey (IMSSV). The IMSS is designed, conducted, and validated by a network of operations strategy scholars. Some of the information below and further details about the survey can be found in several previous studies that used IMSS data, e.g. Voss \& Blackmon (1998), Vecchi \& Brennan (2009), and Da Silveira (2011). The following information has been obtained from the start-up package of IMSS-V and from a summary of proceedings in each country after data collection. Both documents were prepared by the survey's central administration at Politecnico di Milano, Italy and distributed to the network.

IMSS is a global periodic survey of the strategies, practices, and performance of manufacturers of metal parts, machinery, and equipment (ISIC 28-35). The survey is carried out every four or five years. Potential respondents include previous survey participants (to allow longitudinal analyses) and new companies identified in national business databases. The target respondent is the Operations or Manufacturing Director, or equivalent in each business unit.

IMSS-V was carried out in 2009 in 21 countries. The unit of analysis was the business unit, with questions about practices and operations performance referring to the "plant's dominant activity". Across the 21 countries, 7277 companies were initially contacted, of which 4457 received questionnaires. Companies were initially contacted by email or phone. Questionnaires were sent by email in most cases, and by regular post or fax if requested by the company. Eight countries used the original questionnaire in English; 13 countries and the Francophone provinces of Canada used local versions that were in most cases double and reverse translated by academics.
The number of valid responses was 725 (of which 695 were complete for the purposes of this study), i.e. $10.0 \%$ of the initial contacts and $16.3 \%$ of the questionnaires distributed. The countries involved (and valid responses) were Belgium (36), Brazil (37), Canada (19), China (59), Denmark (18), Estonia (27), Germany (38), Hungary (71), Korea (41), Ireland (6), Italy (56), Japan (28), Mexico (17), the Netherlands (51), Portugal (10), Romania (31), Spain (40), Switzerland (31), Taiwan (31), UK (30), and USA (48). Differences in ISIC and size between respondents and non-respondents were checked in seven countries; all tests yielded non-significant results.

\subsection{Cluster formation}

We use cluster analysis to verify the existence of a unique group of mass customizers producing high product variety with high volume process configurations. As discussed, this approach has been used by Safizadeh et al. (1996), Grover \& Malhotra (1999), Ahmad \& Schroeder (2002) and Olhager \& Rudberg (2003), among others. Liu et al. (2006) clustered cases based on MC capability strength as opposed to location in the PPM (Hayes \& Wheelwright, 1979).

Individuals are classified based on a clustering variable denoted $P P D E V$, comprised of two indicators, MASS and CUSTOM. Manufacturers informed the percentage of their production obtained through one-of-a-kind, batch, and mass processes. The indicator MASS is calculated by adding up percentages of each process type for each respondent, using weights $0,0.5$, and 1 , respectively. Manufacturers also informed the percentage of customer orders designed or engineered to order, manufactured to order, assembled to order, or made to stock. The indicator CUSTOM is calculated by adding up percentages of each order type for each respondent, using weights $1,0.67,0.33$, and 0 , respectively. $P P D E V$ is calculated by MASS - (100 - CUSTOM).

The cluster formation procedure is based on the work of Menor et al. (2001) and recommendations in Ketchen \& Shook (1996), and Hair et al. (2010). Based on the rationale in Punj \& Stewart (1983) reviewed by Menor et al. (2001), a two-step method is used. First, hierarchical cluster algorithms are applied to find the best structure for the sample data. Then, $k$-means is used to validate the hierarchical solution. Following recommended practice (e.g. Menor et al., 2001; Tsikriktsis, 2004) we test multiple algorithms in 1BM $^{\circledR}$ SPSS $^{\circledR}$ Statistics 19.0.0 (SPSS, 2010) including between-groups linkage (BGL), within-groups (average) linkage (WGL), the centroid method, and Ward's method, all with squared Euclidean distances. Based on 
agglomeration schedules, cluster sizes, and theoretical interpretability (Menor et al., 2001; Hair et al., 2010), the WGL and Ward's three-cluster solutions provide the best initial configurations. Their means are used as initial seed points to the $k$-means algorithm. The WGL solution has higher stability; thus, the $k$-means three-cluster solution based on seeds from the WGL algorithm is used in the analyses to follow.

\section{Criterion variables}

Hypotheses $\mathrm{H} 2$ to $\mathrm{H} 4$ are tested with objective and perceptual variables. Size $(\mathrm{H} 2)$ is measured by the number of employees in the plant's respective business unit. Location (H3) is measured by four dummies representing continents where plants are situated.

Supplier base $(\mathrm{H} 4)$ is assessed by three independent indicators. Respondents were asked to, "Indicate the following supplier figures [relating to the plant' dominant activity]: Total number of suppliers, Average number of suppliers per item, Proportion of suppliers considered as key/strategic suppliers".

Supplier selection criteria (H5) are assessed by perceptual variables. Respondents were asked, "What criteria do you use for selecting your key/strategic suppliers? Specify the level of importance of each criterion." Responses were provided on a five-point Likert scale with endpoints None (1) and High (5). We use exploratory factor analysis (Table 1) to identify latent criteria reflecting the multiple items of the questionnaire. The analysis identifies three criteria named coordination, responsiveness, and efficiency. The KMO estimate (.720) and Bartlett's significance ( $p<$ .001) suggest the dataset is suitable for factor analysis (Hair et al., 2010). Factor loadings are greater than
.500 and eigenvalues are greater than one. Only one item (logistical costs) loads on more than one factor; the item is retained in Factor 1 for theoretical reasons. The first factor reflects the focus on supply chain integration described in previous studies including the theory leading to $\mathrm{H} 5$. The last two factors have straight correspondence to Fisher's (1997) supply chain framework (even though he considered quality a function of both types of supply chains).

Cronbach's alphas of the multi-item scales are .688 and .629; the later estimate is somewhat low but still consistent with two-item scales (see for example Schwartz (2012)). The former estimate is close to the .70 level recommended in the literature (Peterson, 1994).

\section{Hypothesis tests}

Resulting clusters of individuals are plotted on two-dimensional graphs with MASS (mass process) and CUSTOM (customized production) in the axes, as seen in Figure 1. Three groups of manufacturers are obtained, and their demographics analyzed using two statistical tests: $(i)$ differences between groups in variables 1 to 4 (Table 2) and 9 to 14 (Table 3) are analyzed using Scheffé's method on ANOVA outputs (Sato, 1996; Hair et al., 2010); (ii) differences between groups in variables 5 to 8 (Table 4), which are counts, are analyzed through correspondence analysis (Johnson \& Wichern, 2007).

Group 1, named Process Matchers, is the one best represented in the study sample $(49.78 \%$ of all valid cases). Its members have corresponding product and process structures as prescribed in Hayes \& Wheelwright (1979), being positioned along the main

Table 1. Supplier selection criteria.

\begin{tabular}{|c|c|c|c|}
\hline & \multicolumn{3}{|c|}{ Factor } \\
\hline & 1 & 2 & 3 \\
\hline \multicolumn{4}{|l|}{ Coordination (Cronbach's $\alpha=.688$ ) } \\
\hline Willingness to disclose cost/other information & .785 & .155 & -.054 \\
\hline Physical proximity & .766 & -.070 & .147 \\
\hline Ability to provide innovation and co-design & .638 & .381 & -.262 \\
\hline Logistical costs & .565 & .266 & .428 \\
\hline \multicolumn{4}{|l|}{ Responsiveness (Cronbach's $\alpha=.629$ ) } \\
\hline Quality of products/services & .056 & .869 & -.100 \\
\hline Delivery performance & .199 & .773 & .294 \\
\hline \multicolumn{4}{|l|}{ Efficiency } \\
\hline Lowest price bid & -.017 & .029 & .907 \\
\hline \multicolumn{4}{|l|}{ Rotation sum of squared loadings } \\
\hline Eigenvalue & 1.973 & 1.598 & 1.195 \\
\hline Cumulative $\%$ of Variance & 28.179 & 51.010 & 68.080 \\
\hline
\end{tabular}

Principal Component Analysis with Varimax rotation. Listwise deletion of cases with missing values $(n=690)$. KMO $=.720$; Bartlett's test $p<.001$. Factor loadings $\geq .400$ in bold. 

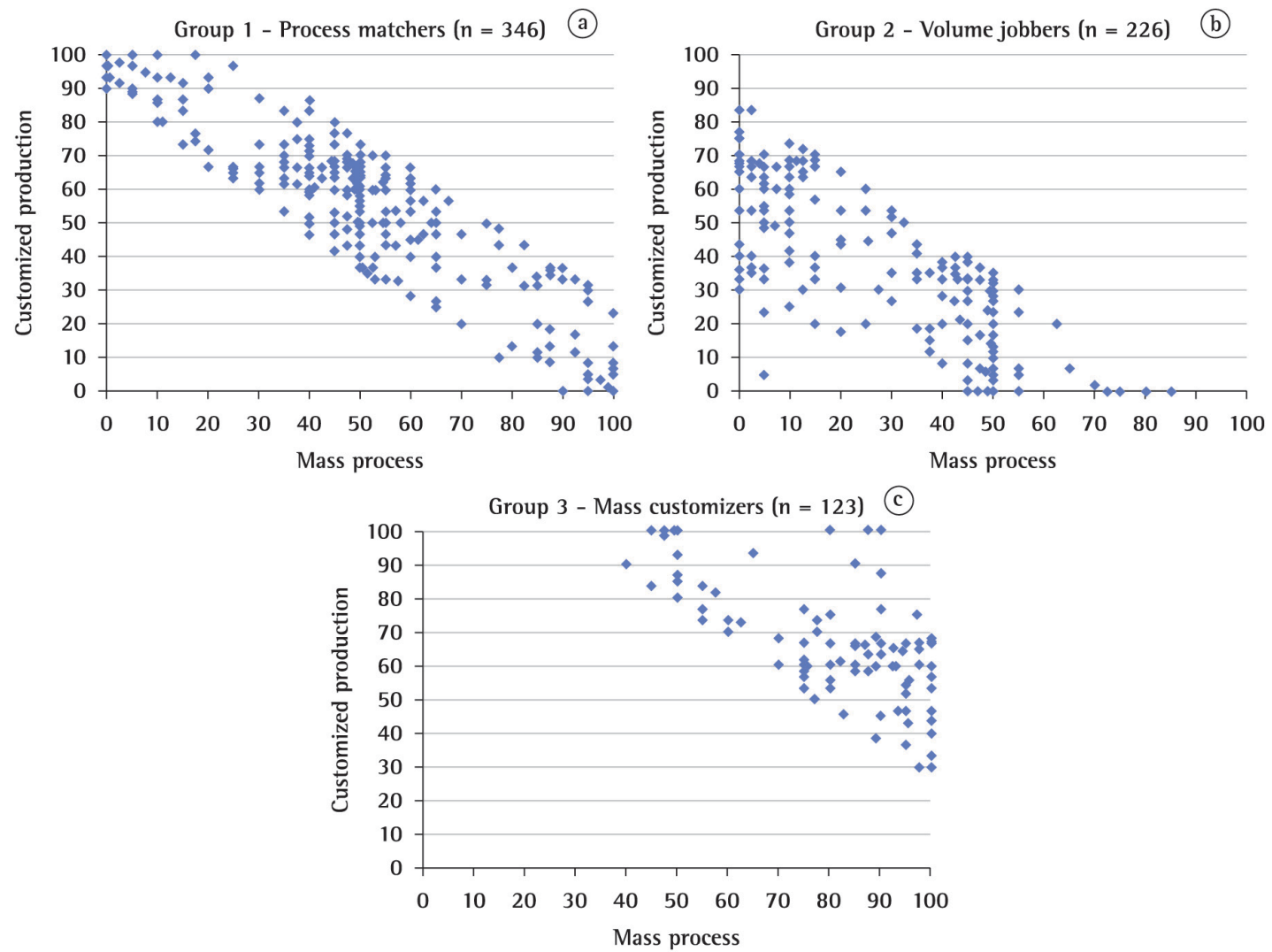

Figure 1. Process-product choices in the three clusters.

Table 2. Process configuration, variables 1 to 4.

\begin{tabular}{|c|c|c|c|c|c|}
\hline Group & $\begin{array}{c}1 \\
\text { Process Matchers }\end{array}$ & $\begin{array}{c}2 \\
\text { Volume Jobbers }\end{array}$ & $\begin{array}{c}3 \\
\text { Mass Customizers }\end{array}$ & Total & $\begin{array}{c}F \text {-value } \\
\text { ( } p \text {-value })\end{array}$ \\
\hline Valid $n^{\prime}$ & 346 & 226 & 123 & 695 & \\
\hline \multicolumn{6}{|l|}{ PPDEV } \\
\hline Mean $^{2}$ & $6.20\left[2,3^{*}\right]$ & $-34.31\left[1,3^{*}\right]$ & $47.32\left[1,2^{*}\right]$ & .30 & 1693.665 \\
\hline S.D. & 10.93 & 14.43 & 14.38 & 31.03 & $(<.001)$ \\
\hline \multicolumn{6}{|l|}{ MASS } \\
\hline Mean ${ }^{2}$ & $47.61\left[2,3^{*}\right]$ & $27.26\left[1,3^{*}\right]$ & $82.60\left[1,2^{*}\right]$ & 47.18 & 240.716 \\
\hline S.D. & 24.42 & 21.66 & 17.99 & 29.28 & $(<.001)$ \\
\hline \multicolumn{6}{|l|}{ CUSTOM } \\
\hline Mean ${ }^{2}$ & $58.59\left[2,3^{*}\right]$ & $38.43\left[1,3^{*}\right]$ & $64.72\left[1,2^{*}\right]$ & 53.12 & 77.443 \\
\hline S.D. & 23.15 & 22.05 & 18.98 & 24.42 & $(<.001)$ \\
\hline Employees' & 344 & 224 & 121 & 689 & \\
\hline Mean ${ }^{2}$ & 1566.49 & 1848.00 & 2387.57 & 1802.20 & .411 \\
\hline S.D. & 7830.57 & 10707.57 & 6017.40 & 8610.22 & $(.663)$ \\
\hline
\end{tabular}

'Casewise deletion of observations with missing values; valid $n$ reported next to variable when different from baseline. ${ }^{2}$ Highest cluster mean is in bold; numbers in brackets indicate clusters with significant mean differences based on post-hoc Scheffé ( $\left.{ }^{*} p<.001\right)$.

diagonal of the $\mathrm{M} \times \mathrm{C}$ graph, with indicators MASS (mass process) and CUSTOM (customized production) in the horizontal and vertical axes, respectively (Figure 1a). Process matchers are distributed evenly across regions with no significant differences, although Asian and North American manufacturers are slightly better represented in the group, in opposition to European and South American companies. The cluster mean with respect to PPDEV is 6.20; a zero value would correspond to a perfectly diagonal distribution of individuals in the $\mathrm{M} \times \mathrm{C}$ graph. Indicators MASS and CUSTOM display averages of 47.61 and 58.59, respectively, resulting in individuals slightly more concentrated above the main diagonal. Average 
Table 3. Supply chain management, variables 9 to 14.

\begin{tabular}{|c|c|c|c|c|c|}
\hline Group & $\stackrel{1}{1}$ Process Matchers & $\begin{array}{c}2 \\
\text { Volume Jobbers }\end{array}$ & $\begin{array}{c}3 \\
\text { Mass Customizers }\end{array}$ & Total & $\begin{array}{c}F \text {-value } \\
\text { ( } p \text {-value) }\end{array}$ \\
\hline Valid $n^{1}$ & 346 & 226 & 123 & 695 & \\
\hline No. of suppliers' & 290 & 183 & 96 & 671 & \\
\hline Mean $^{2}$ & $270.93[3+]$ & $302.24\left[3^{*}\right]$ & $127.84\left[1+, 2^{*}\right]$ & 256.86 & 3.641 \\
\hline S.D. & 614.61 & 495.16 & 209.45 & 530.73 & $(.027)$ \\
\hline Suppliers per item ${ }^{1}$ & 280 & 178 & 94 & 569 & \\
\hline Mean $^{2}$ & 9.71 & 12.64 & 10.14 & 10.73 & .406 \\
\hline S.D. & 33.15 & 40.57 & 25.56 & 34.60 & (.667) \\
\hline Strategic suppliers' & 288 & 183 & 91 & 562 & \\
\hline Mean ${ }^{2}$ & $32.18\left[3^{*}\right]$ & $27.93\left[3^{*}\right]$ & $39.97\left[1^{*}, 2^{*}\right]$ & .11 & 6.281 \\
\hline S.D. & 26.27 & 24.94 & 30.05 & .32 & $(.002)$ \\
\hline Efficiency' & 339 & 218 & 119 & 676 & 1.469 \\
\hline Mean ${ }^{2}$ & 3.57 & 3.42 & 3.50 & 3.51 & $(.231)$ \\
\hline S.D. & .97 & 1.01 & 1.16 & 1.02 & \\
\hline Responsiveness ${ }^{1}$ & 340 & 216 & 119 & 675 & 2.156 \\
\hline Mean $^{2}$ & 4.22 & 4.14 & 4.08 & 4.17 & $(.117)$ \\
\hline S.D. & .68 & .67 & .75 & .69 & \\
\hline Coordination & 334 & 215 & 118 & 667 & 5.012 \\
\hline Mean $^{2}$ & $3.04[1+]$ & $2.85\left[1+, 3^{*}\right]$ & $3.07\left[2^{*}\right]$ & 2.98 & (.007) \\
\hline S.D. & .81 & .71 & .79 & .78 & \\
\hline
\end{tabular}

${ }^{1}$ Casewise deletion of observations with missing values; valid $n$ reported next to variable. ${ }^{2}$ Highest cluster mean is in bold; numbers in brackets indicate clusters with significant mean differences based on post-hoc Scheffé $(* 0<.05 ;+p<.10)$.

Table 4. Geographic location, variables 5 to 8 .

\begin{tabular}{|c|c|c|c|c|c|}
\hline Group & $\begin{array}{c}1 \\
\text { Process Matchers }\end{array}$ & $\stackrel{2}{2}$ Volume Jobbers & $\begin{array}{c}3 \\
\text { Mass Customizers }\end{array}$ & Total & $\begin{array}{c}\chi^{2} \text { value } \\
(p \text {-value })\end{array}$ \\
\hline Valid $n^{1}$ & 346 & 226 & 123 & 695 & \\
\hline \multicolumn{6}{|l|}{ Europe } \\
\hline$\chi^{2}$ value & 0.03 & 3.01 & 4.18 & 7.2 & \\
\hline Standardized residual ${ }^{2}$ & -0.40 & 3.29 & -3.51 & & \\
\hline \multicolumn{6}{|l|}{ Asia } \\
\hline$\chi^{2}$ value & 0.04 & 9.61 & 14.93 & 24.6 & \\
\hline Standardized residual ${ }^{2}$ & 0.33 & -4.36 & 4.92 & & \\
\hline \multicolumn{6}{|l|}{ N. America } \\
\hline$\chi^{2}$ value & 0.04 & 0.01 & 0.05 & 0.1 & \\
\hline Standardized residual $^{2}$ & 0.28 & -0.09 & -0.25 & & \\
\hline \multicolumn{6}{|l|}{ S. America } \\
\hline$\chi^{2}$ value & 0.01 & 1.15 & 1.65 & 2.8 & \\
\hline Standardized residual $^{2}$ & -0.15 & 1.34 & -1.45 & & \\
\hline
\end{tabular}

'Casewise deletion of observations with missing values. ${ }^{2}$ Absolute standardized residuals larger than \pm 2.0 and \pm 3.0 (in bold) are significant at $5 \%$ and $1 \%$, respectively.

company size in the group is 1566.49 employees, not differing significantly from the other two groups.

Group 2, named Volume Jobbers, includes 226 manufacturers of products with medium to low levels of customization, using batch or one-of-a-kind production systems, and positioned below the main diagonal in the $\mathrm{M} \times \mathrm{C}$ graph (Figure $1 \mathrm{~b}$ ). European manufacturers are significantly more present in this group, whereas Asian manufacturers are significantly less present. As expected, individuals are concentrated below but yet close to the main diagonal, with indicators MASS and CUSTOM presenting averages of
27.26 and 38.43 , respectively; only six manufacturers in the group are positioned in the quadrant where indicators are below 25\%.

Group 3, named Mass Customizers, includes 123 manufacturers that make products with medium to high levels of customization using mass production processes, being positioned above the main diagonal in the $\mathrm{M} \times \mathrm{C}$ graph (Figure 1c). Asian manufacturers are significantly more present in this group, whereas European manufacturers are significantly less present. Individuals are slightly more concentrated in the lower portion of the triangle above the main diagonal; that 
is reflected in the averages of MASS and CUSTOM for this group: 82.60 and 64.72 , respectively.

We next investigate whether size of the plant's business unit varies with adoption of a MC strategy. Group 1's rounded average size is 1566 employees; for companies in groups 2 and 3 the rounded averages are 1848 and 2388, respectively. Scheffé's test indicates no significant differences in size in the three groups.

The results provide mixed support to our hypotheses. Hypothesis 1 is supported as the cluster analysis clearly separates between MC (Group 3) and non-MC (Groups 1 and 2) manufacturers. Hypothesis 2 is supported as there are no significant differences in business unit size across clusters. Hypothesis 3 is not supported as, based on results in Table 2, MC is more frequently found in Asian companies and less frequently found in European companies.

Finally we test for differences in supply chain configuration between $\mathrm{MC}$ and non-MC groups (Table 3). The test of $\mathrm{H} 4$ is based on variables 9 to 11. The average number of suppliers (variable 9) in Group 3 (127.84) is significantly smaller than those in Group 1 (270.93) and Group 2 (302.24). The number of suppliers per item (variable 10) is not significantly different across groups. However, the number of strategic suppliers (variable 11) is significantly larger in Group 3 (39.97) than in Group 1 (32.18) and Group 2 (27.93).

The $\mathrm{H} 5$ test follows the analysis of variables 12 to 14 . There were no significant differences between groups with respect to the importance attributed to efficiency (variable 12) or responsiveness (variable 13) as supplier selection criteria. However, MC plants in Group 3 gave significantly more importance to coordination criteria (variable $14, \mu=3.07$ ) than plants in Group 2 (2.85), even though their mean score was not significantly different from that in Group 1 (3.04).

This analysis provides good support to $\mathrm{H} 4$ but partial support to H5. Despite the similar number of suppliers per item, plants in MC group did maintain closer relationships with more suppliers than plants in the other groups, and their supplier base was smaller than in other groups. As a ratio, Group 3 maintained strategic relationships with $31 \%$ of their suppliers on average, compared to $11 \%$ in Group 1 and 9\% in Group 2. On the other hand, results provide only limited support to H5, as MC companies in Group 3 attribute more importance to coordination criteria in supplier selection than companies in Group 2 but not in Group 1.

\section{Discussion}

One of the study contributions is providing further validation to Hayes \& Wheelwright's (1979) PPM. Our analysis identifies manufacturing strategy configurations across a large sample of manufacturers and indicates that about half of the observations fit on the matrix main diagonal.

However, the analysis also identifies several observations operating off the diagonal. In particular, the existence of Group 3 provides evidence to the wide adoption of $\mathrm{MC}$ as shown in previous studies (Safizadeh et al., 1996; Grover \& Malhotra, 1999; Ahmad \& Schroeder, 2002; Olhager \& Rudberg, 2003). As stated earlier, manufacturing process innovations in modularity design (Ro et al., 2007), CAD and rapid prototyping (Gould, 2004; McMains, 2005), and rapid manufacturing (Atzeni et al., 2010) enable manufacturing companies to produce high product varieties in high volume process configurations (Svensson \& Barfood, 2002).

Our analysis supports the view in Hayes \& Wheelwright (1979) that product and process configuration rather than company size is a determinant of manufacturing strategy. We find that company size does not vary significantly across the three clusters in Figure 1. However, geography may explain MC adoption in manufacturing. The significant prevalence of Asian over European companies in the Mass Customizers group may indicate that environmental factors such as market and industry variables influence $\mathrm{MC}$ implementation. In particular, manufacturers located in Asia might pursue MC to cater to a sizeable population with largely diverse values and expectations (see, for example, Kwon's (2012) analysis of cultural differences among employees from different regions of China). Differences in personal cultural profiles within and across Asian countries might lead to higher demand for MC products and services. This proposition might be tested in future studies exploring market antecedents of MC.

Results further indicate that, compared to the other groups, MC providers give more emphasis to developing collaborative relationships with suppliers. Moreover, they have fewer suppliers in total, but more strategic suppliers than any of the two other groups. This is evidence that MC providers give more preference to collaborative (as opposed to arms-length) modes of supply chain governance than any other group in the sample. As indicated in our theoretical framework, these results are consistent with the literature on MC and with basic tenets of transaction cost economics (TCE) (Williamson, 1985) and the extended resourcebased view of the firm (ERBV; Lai et al., 2012), as will be discussed.

Two elements in particular may promote the use of collaborative governance by MC providers. Perhaps the more significant is, as indicated by Lai et al. (2012) and Trentin et al. (2012), the inherent uncertainty about the variety and volume of market demand, 
and consequently sourcing requirements of $\mathrm{MC}$ firms. As pointed out by Liao et al. (2011) and Peng et al. (2011) among others, MC providers and their suppliers must exchange information more frequently and in higher volume to convey frequent demand changes such as in design specifications, order volumes, and production schedules. As explained by TCE studies such as Malone (1987) and Clemons et al. (1993), such levels of communication might turn coordination costs too expensive under traditional (i.e. arms-length) relationships, and require the development of closer associations with fewer suppliers. Our findings provide clear evidence of such relationships in the case of $\mathrm{MC}$ providers.

The second element is based on the ERBV precept of searching for external sources of resources and capabilities to the firm (Lai et al., 2012). Competing on $\mathrm{MC}$ requires developing various technologies (Da Silveira et al., 2001) and achieving competitive advantages in multiple performance dimensions (Lai et al., 2012; Trentin et al., 2012). Since individual firms may find it difficult to develop expertise and excellence across many areas simultaneously, they may benefit significantly from partnering with suppliers that are sources of complementary expertise or knowledge. As indicated by Da Silveira (2011), network theory studies such as Jones et al. (1997) suggest that such knowledge exchange between supply chain partners depends on more integrated relationships such as those associated with the MC group in the study findings.

\section{Conclusions}

The study investigates the demographic configuration of $\mathrm{MC}$ providers in an international survey of manufacturers of metal products, equipment and instruments. Results indicate that compared to other manufacturing groups, MC producers (i) are more frequently located in Asia and less in Europe and (ii) have fewer suppliers with whom they developed more collaborative relationships. However, the analysis provides no significant evidence that size of the busines units of MC plants is significantly different from the other groups.

Even though the study focuses on one particular manufacturing sector, its findings may contribute to improve understanding of MC development across the world. Whereas the earlier literature often focused on describing specific cases of implementation, the significant dissemination of $\mathrm{MC}$ across the world requires more systematic analyses of $\mathrm{MC}$ adopters and their supply chains. This study is aimed at contributing towards that line of research.
The study is based on a parsimonious framework that albeit focusing on key demographic variables does not exhaust the need for further explorations. Future studies should not only replicate our analyses across different industries but also explore additional variables of relevance such as markets and distribution channels of MC providers around the world. Such knowledge will advance our understanding of the nature of $\mathrm{MC}$ implementations and subsequently the challenges associated with this production approach.

Our findings have important implications to academics and practitioners. Considering that approximately $50 \%$ of the individuals in the study sample appear to operate off the PPM main diagonal, further research is needed to specify the antecedents, particularly technology and practices enabling adoption and success with those configurations. From a management perspective, our findings indicate that the choice of product and process may be aligned to peculiarities of regional markets and industries; for example, in determining the means and extent of MC capability development.

The study has limitations indicating future research opportunities. Since data are obtained from a crosssectional survey, hypotheses of causality could not be tested. Due to the exploratory nature of the study, further analyses based on confirmatory regression and structural equation modeling might provide further validation to our hypotheses.

\section{References}

Ahmad, S., \& Schroeder, R. G. (2002). Refining the productprocess matrix. International Journal of Operations \& Production Management, 22(1), 103-124. http://dx.doi. org/10.1108/01443570210412097

Ahmad, S., Schroeder, R. G., \& Mallick, D. N. (2010). The relationship among modularity, functional coordination, and mass customization. European Journal of Innovation Management, 13(1), 46-61. http://dx.doi. org/10.1108/14601061011013221

Aigbedo, H. (2009). A note on parts inventory and mass customization for a two-stage JIT supply chain with zero-one type of bills of materials. Journal of the Operational Research Society, 60(9), 1286-1291. http:// dx.doi.org/10.1057/palgrave.jors.2602640

Ariss, S. S., \& Zhang, Q. (2002). The impact of flexible process capability on the product-process matrix: an empirical examination. International Journal of Production Economics, 76(2), 135-145. http://dx.doi.org/10.1016/ S0925-5273(01)00146-3

Atzeni, E., luliano, L., Minetola, P., \& Salmi, A. (2010). Redesign and cost estimation of rapid manufactured plastic parts. Rapid Prototyping Journal, 16(5), 308-317. http://dx.doi.org/10.1108/13552541011065704

$\mathrm{Au}$, C. K., \& Ma, Y.-S. (2010). Garment pattern definition, development and application with associative feature approach. Computers in Industry, 61(6), 524-531. http:// dx.doi.org/10.1016/j.compind.2010.03.002 
Barlow, J., Childerhouse, P., Gann, D., Hong-Minh, S., Naim, M., \& Ozaki, R. (2003). Choice and delivery in housebuilding: lessons from Japan for UK housebuilders. Building Research \& Information, 31(2), 134-145. http:// dx.doi.org/10.1080/09613210302003

Bateman, R. J., \& Cheng, K. (2006). Extending the product portfolio with 'devolved manufacturing': methodology and case studies. International Journal of Production Research, 44(16), 3325-3343. http://dx.doi. org/10.1080/00207540500536947

Boyer, K. K., Ward, P. T., \& Leong, G. K. (1996). Approaches to the factory of the future an empirical taxonomy. Journal of Operations Management, 14(4), 297-313. http://dx.doi.org/10.1016/S0272-6963(96)00093-9

Clemons, E. K., Reddi, S. P., \& Row, M. C. (1993). The impact of information technology on the organization of economic activity: the 'move to the middle' hypothesis. Journal of Management Information Systems, 10(2), 9-35.

Da Silveira, G. J. C. (2011). Our own translation box: exploring proximity antecedents and performance implications of customer co-design in manufacturing. International Journal of Production Research, 49(13), 3833-3854. http://dx.doi.org/10.1080/00207543.2010.492801

Da Silveira, G., Borenstein, D., \& Fogliatto, F. S. (2001). Mass customization: literature review and research directions. International Journal of Production Economics, 72(1), 1-13. http://dx.doi.org/10.1016/ S0925-5273(00)00079-7

Davis, S. M. (1987). Future perfect. Reading: Addison-Wesley.

Dean, P. R., Tu, Y. L., \& Xue, D. (2009). An information system for one-of-a-kind production. International Journal of Production Research, 47(4), 1071-1087. http://dx.doi. org/10.1080/00207540701543593

Dewan, R., Jing, B., \& Seidmann, A. (2003). Product customization and price competition on the internet. Management Science, 49(8), 1055-1070. http://dx.doi. org/10.1287/mnsc.49.8.1055.16401

Duray, R. (2002). Mass customization origins: mass or custom manufacturing? International Journal of Operations \& Production Management, 22(3), 314-328. http://dx.doi. org/10.1108/01443570210417614

Fan, Y. S., \& Huang, G. Q. (2007). Networked manufacturing and mass customization in the ECommerce era: the Chinese perspective. International Journal of Computer Integrated Manufacturing, 20(2), 107-114. http://dx.doi. org/10.1080/09511920601020631

Feitzinger, E., \& Lee, H. L. (1997). Mass customization at Hewlett-Packard: the power of postponement. Harvard Business Review, 75(1), 116-121.

Fisher, M. L. (1997). What is the right supply chain for your product? Harvard Business Review, 75(2), 105-116.

Franke, N., \& Schreier, M. (2008). Product uniqueness as a driver of customer utility in mass customization. Marketing Letters, 19(2), 93-107. http://dx.doi. org/10.1007/s11002-007-9029-7

Galbraith, J. R. (1977). Organization design. Reading: Addison-Wesley.

Gilmore, J. H., \& Pine 11, B. J. (1997). The four faces of mass customization. Harvard Business Review, 75(1), 91-101.

Gould, L. S. (2004). Rapid prototyping: bigger and stronger. Automotive Design \& Production, 116(11), 52-53.

Grover, V., \& Malhotra, M. K. (1999). A framework for examining the interface between operations and information systems: implications for research in the new millennium. Decision Sciences, 30(4), 901-920. http:// dx.doi.org/10.1111/j.1540-5915.1999.tb00913.x
Hair, J. F. J., Black, W. C., Babin, B. J., \& Anderson, R. E. (2010). Multivariate data analysis. Upper Saddle River: Pearson Prentice Hall.

Hayes, R. H., \& Wheelwright, S. C. (1979). Link manufacturing process and product life cycles. Harvard Business Review, 57(1), 133-140.

Johnson, R. A., \& Wichern, D. W. (2007). Applied multivariate statistical analysis. Upper Saddle River: Pearson Prentice Hall.

Jones, C., Hesterly, W. S., \& Borgatti, S. P. (1997). A general theory of network governance: exchange conditions and social mechanisms. The Academy of Management Review, 22(4), 911-945.

Kincade, D. H., Regan, C., \& Gibson, F. Y. (2007). Concurrent engineering for product development in mass customization for the apparel industry. International Journal of Operations \& Production Management, 27(6), 627-649. http://dx.doi. org/10.1108/01443570710750295

Ketchen , D. J., \& Shook, C. L. (1996). The application of cluster analysis in strategic management research: an analysis and critique. Strategic Management Journal, 176), 441-458. http:// dx.doi.org/10.1002/(SICI)1097-0266(199606)17:6<441::AIDSMJ819>3.0.CO;2-G

Kotha, S. (1995). Mass customization: implementing the emerging paradigm for competitive advantage. Strategic Management Journal, 16(S1), 21-42. http://dx.doi. org/10.1002/smj.4250160916

Koufteros, X. A., Edwin Cheng, T. C., \& Lai, K. (2007). "Black-box" and "gray-box" supplier integration in product development: Antecedents, consequences and the moderating role of firm size. Journal of Operations Management, 25(4), 847-870. http://dx.doi. org/10.1016/j.jom.2006.10.009

Kwon, J.-W. (2012). Does China have more than one culture? Asia Pacific Journal of Management, 29(1), 79-102. http://dx.doi.org/10.1007/s10490-010-9191-y

Lai, F., Zhang, M., Lee, D. M. S., \& Zhao, X. (2012). The impact of supply chain integration on mass customization capability: an extended resource-based view. IEEE Transactions on Engineering Management, 59(3), 443456. http://dx.doi.org/10.1109/TEM.2012.2189009

Liao, K., Ma, Z., Lee, J. J.-Y., \& Ke, K. (2011). Achieving mass customization through trust-driven information sharing: a supplier's perspective. Management Research Review, 34(5), 541-552. http://dx.doi. org/10.1108/01409171111128715

Liu, G., Shah, R., \& Schroeder, R. |G. (2006). Linking work design to mass customization: a sociotechnical systems perspective. Decision Sciences, 37(4), 519-545. http:// dx.doi.org/10.1111/j.1540-5414.2006.00137.x

Malone, T. W. (1987). Modeling coordination in organizations and markets. Management Science, 33(10), 1317-1332. http://dx.doi.org/10.1287/mnsc.33.10.1317

Matzler, K., Stieger, D., \& Füller, J. (2011). Consumer confusion in internet-based mass customization: Testing a network of antecedents and consequences. Journal of Consumer Policy, 34(2), 231-247. http://dx.doi. org/10.1007/s10603-011-9157-6

Mclntosh, R. 1., Matthews, J., Mullineux, G., \& Medland, A. J. (2010). Late customisation: issues of mass customisation in the food industry. International Journal of Production Research, 48(6), 1557-1574. http://dx.doi. org/10.1080/00207540802577938

McMains, S. (2005). Layered manufacturing technologies. Communications of the ACM, 48(6), 50-56. http:// dx.doi.org/10.1145/1064830.1064858 
Menor, L. J., Roth, A. V., \& Mason, C. H. (2001). Agility in retail banking: a numerical taxonomy of strategic service groups. Manufacturing \& Service Operations Management, 3(4), 273-292. http://dx.doi.org/10.1287/ msom.3.4.273.9969

Merle, A., Chandon, J., \& Roux, E. (2008). Understanding the perceived value of mass customization: the distinction between product value and experiential value of co-design. Recherche et Applications en Marketing, 23(3), 27-50. http://dx.doi.org/10.1177/076737010802300301

Mikkola, J. H., \& Skjott-Larsen, T. (2004). Supply-chain integration: Implications for mass customization, modularization, and postponement strategies. Production Planning \& Control, 15(4), 352-361. http:// dx.doi.org/10.1080/0953728042000238845

Olhager, J., \& Rudberg, M. (2003). Manufacturing strategy and e-business: an exploratory study. Integrated Manufacturing Systems, 14(4), 334-345. http://dx.doi. org/10.1108/09576060310469716

Ong, S. K., Lin, Q., \& Nee, A. Y. C. (2006). Web-based configuration design system for product customization. International Journal of Production Research, 44(2), 351 382. http://dx.doi.org/10.1080/00207540500244153

Pallari, J. H. P., Dalgarno, K. W., \& Woodburn, J. (2010). Mass customization of foot orthoses for rheumatoid arthritis using selective laser sintering. IEEE Transactions on Biomedical Engineering, 57(7), 17501756. PMid:20211798. http://dx.doi.org/10.1109/ TBME.2010.2044178

Peng, D. X., Liu, G., \& Heim, G. R. (2011). Impacts of information technology on mass customization capability of manufacturing plants. International Journal of Operations \& Production Management, 31(10), 10221047. http://dx.doi.org/10.1108/01443571111182173

Peterson, R.A. (1994). A meta-analysis of Cronbach's coefficient alpha. Journal of Consumer Research, 21(2), 381-391. http://dx.doi.org/10.1086/209405

Pine Il, B. J., Peppers, D., \& Rogers, M. (1995). Do you want to keep your customers forever? Harvard Business Review, 73(2), 103-114.

Pine 1l, B. J. (1993). Mass customization: the new frontier in business competition. Boston: Harvard Business Press.

Punj, G., \& Stewart, D. W. (1983). Cluster analysis in marketing research: review and suggestions for application. Journal of Marketing Research, 20(2), 134-148. http://dx.doi. $\operatorname{org} / 10.2307 / 3151680$

Ro, Y. K., Liker, J. K., \& Fixson, S. K. (2007). Modularity as a strategy for supply chain coordination: the case of U.S. auto. IEEE Transactions on Engineering Management, 54(1), 172-189. http://dx.doi.org/10.1109/ TEM.2006.889075

Safizadeh, M. H., Ritzman, L. P., Sharma, D., \& Wood, C. (1996). An empirical analysis of the product-process matrix. Management Science, 42(11), 1576-1591. http:// dx.doi.org/10.1287/mnsc.42.11.1576

Salvador, F., Rungtusanatham, M., \& Forza, C. (2004). Supply-chain configurations for mass customization. Production Planning \& Control, 15(4), 381-397. http:// dx.doi.org/10.1080/0953728042000238818

Sato, T. (1996). Type 1 and type 11 error in multiple comparisons. Journal of Psychology, 130(3), 293-302. http://dx.doi.org/10.1080/00223980.1996.9915010

Schwab, K., \& Sala-i-Martin, X. (2011). The Global Competitiveness Report 2011-2012. Geneva: World Economic Forum.
Schwartz, S. H. (2012). Human values. Norway: European Social Survey Education Net. Retrieved from http:// essedunet.nsd.uib.no/cms/topics/1/

SPSS. (2010). IBM SPSS Statistics 19 Core System User's Guide. Chicago.

Su, J. C. P., Chang, Y., \& Ferguson, M. (2005). Evaluation of postponement structures to accommodate mass customization. Journal of Operations Management, 23(3), 305-318. http://dx.doi. org/10.1016/j.jom.2004.10.016

Svensson, C., \& Barfod, A. (2002). Limits and opportunities in mass customization for 'build to order' SMEs. Computers in Industry, 49(1), 77-89. http://dx.doi.org/10.1016/ S0166-3615(02)00060-X

Trentin, A., Forza, C., \& Perin, E. (2012). Organization design strategies for mass customization: an informationprocessing-view perspective. International Journal of Production Research, 50(14), 3860-3877. http://dx.doi. org/10.1080/00207543.2011.597790

Tsikriktsis, N. (2004). A technology readiness-based taxonomy of customers: a replication and extension. Journal of Service Research, 71), 42-52. http://dx.doi. org/10.1177/1094670504266132

Tu, Q., Vonderembse, M. A., Ragu-Nathan, T. S., \& RaguNathan, B. (2004). Measuring modularity-based manufacturing practices and their impact on mass customization capability: a customer-driven perspective. Decision Sciences, 35(2), 147-168. http://dx.doi. $\operatorname{org} / 10.1111 / j .00117315 .2004 .02663 . x$

Vecchi, A., \& Brennan, L. (2009). A cultural perspective on innovation in international manufacturing. Research in International Business \& Finance, 23(2), 181-192. http:// dx.doi.org/10.1016/j.ribaf.2008.03.008

Voss, C., \& Blackmon, K. (1998). Differences in manufacturing strategy decisions between Japanese and Western manufacturing plants: the role of strategic time orientation. Journal of Operations Management, 16(2), 147-158. http://dx.doi.org/10.1016/ S0272-6963(97)00034-X

Williamson, 0. E. (1985). The economic institutions of capitalism. New York: Free Press.

Wind, J., \& Rangaswamy, A. (2001). Customerization: the next revolution in mass customization. Journal of Interactive Marketing, 15(1), 13-32. http://dx.doi. org/10.1002/1520-6653(200124)15:1<13::AlDDIR1001>3.0.CO;2-\#

Yang, D. T., Chen, V. W., \& Monarch, R. (2010). Rising wages: has China lost its global labor advantage? Pacific Economic Review, 15(4), 482-504. http://dx.doi. org/10.1111/j.1468-0106.2009.00465.x

Zipkin, P. (2001). The limits of mass customization. MIT Sloan Management Review, 42(3), 81-87.

\section{Acknowledgements}

A shorter version of this paper appeared in the Proceedings from the 4th Production and Operations Management World Conference, Amsterdam, 2012. Giovani J.C. da Silveira's research is supported by the Warren \& Marline Dyer Faculty Fellowship in Operations Management at the Haskayne School of Business. Flavio S. Fogliatto's research is supported by CNPq (Brazilian Council of Research and Technology) through grant \# 303059/2011-7. 